\title{
Use of 3D Navigation in Subaxial Cervical Spine Lateral Mass Screw Insertion
}

\author{
${ }^{1}$ Division of Orthopaedic and Division of Neurosurgery, The Ottawa Hospital, \\ University of Ottawa Combined Spine Program, Ottawa, Ontario, Canada \\ 2 Division of Orthopaedic Surgery, The Ottawa Hospital, Ottawa, \\ Ontario, Canada \\ ${ }^{3}$ Faculty of Medicine, University of Ottawa, Ottawa, Ontario, Canada \\ ${ }^{4}$ Clinical Epidemiology Program, Ottawa Hospital Research Institute, \\ Ottawa, Ontario, Canada \\ ${ }^{5}$ Division of Neurosurgery, The Ottawa Hospital, Ottawa, Ontario, Canada
}

Abdullah Arab ${ }^{1,2}$ Fahad Alkherayf ${ }^{1,3,4,5}$ Adam Sachs ${ }^{1,3,5}$ Eugene K. Wai ${ }^{1,2,3,4}$

\author{
Address for correspondence Abdullah Arab, MD, The Ottawa \\ Hospital, University of Ottawa Combined Spine Program, Ottawa, \\ Ontario, Canada \\ (e-mail: drabdullaharab@gmail.com; abarab@toh.on.ca).
}

J Neurol Surg Rep 2018;79:e1-e8.

\section{Abstract}

Keywords

- freehand

- lateral mass screw

- 3D navigation

- cervical spine

- subaxial spine

- fixation complication

Objective Cervical spine can be stabilized by different techniques. One of the common techniques used is the lateral mass screws (LMSs), which can be inserted either by freehand techniques or three-dimensional (3D) navigation system. The purpose of this study is to evaluate the difference between the 3D navigation system and the freehand technique for cervical spine LMS placement in terms of complications. Including intraoperative complications (vertebral artery injury [VAI], nerve root injury [NRI], spinal cord injury [SCI], lateral mass fracture [LMF]) and postoperative complications (screw malposition, screw complications).

Methods Patients who had LMS fixation for their subaxial cervical spine from January 2014 to April 2015 at the Ottawa Hospital were included. A total of 284 subaxial cervical LMS were inserted in 40 consecutive patients. Surgical indications were cervical myelopathy and fractures. The screws' size was $3.5 \mathrm{~mm}$ in diameter and 8 to $16 \mathrm{~mm}$ in length. During the insertion of the subaxial cervical LMS, the 3D navigation system was used for 20 patients, and the freehand technique was used for the remaining 20 patients. We reviewed the charts, X-rays, computed tomography (CT) scans, and follow-up notes for all the patients pre- and postoperatively.

Results Postoperative assessment showed that the incidence of $\mathrm{VAI}, \mathrm{SCl}$, and NRI were the same between the two groups. The CT scan analysis showed that the screw breakage, screw pull-outs, and screw loosening were the same between the two groups. LMF was less in the 3D navigation group but statistically insignificant. Screw malposition was less in the 3D navigation group compared with the freehand group and was statistically significant. The hospital stay, operative time, and blood loss were statistically insignificant between the two groups.

Conclusions The use of CT-based navigation in LMS insertion decreased the rate of screw malpositions as compared with the freehand technique. Further investigations and trials will determine the effect of malpositions on the c-spine biomechanics. The use of navigation in LMS insertion did not show a significant difference in VAI, LMF, SCI, or NRI as compared with the freehand technique.
\end{abstract}

received

April 5, 2017

accepted

November 30, 2017
DOI https://doi.org/

10.1055/s-0038-1624574. ISSN 2193-6358. (c) 2018 Georg Thieme Verlag KG Stuttgart · New York
License terms

(c) (i) $\ominus$ (\$) 


\section{Introduction}

Different techniques have been used for posterior stabilization of the cervical spine; some of these techniques include interlaminar wiring, lateral mass screw (LMS), and pedicle screws. ${ }^{1}$ LMS fixation is one of the common techniques used for treating unstable cervical spine due to different pathologies such as trauma, rheumatoid arthritis, tumors, osteoarthritis, etc. Compared with other cervical spine stabilization techniques, LMS fixation has been proven to be effective and safe. ${ }^{1}$ This technique requires a posterior cervical approach with a dissection through the paraspinal muscles. In addition, bony landmarks have to be outlined prior to any LMS instrumentation.

Polyaxial screws have enabled angulated trajectories for placing longer screws toward the superior-lateral-ventral corner of the lateral mass. ${ }^{2}$ In addition, the improvement in LMS constructs, from posterior cervical plating to rodbased systems, has provided additional advantages such as greater amenability to multiplanar contouring, increased flexibility for extending to the occiput or the thoracic spine, and more precise screw placement. ${ }^{2}$

Roy-Camille et al was the first to insert an LMS in the cervical spine in 1979. ${ }^{2,3}$

In the following years, LMS instrumentation has been described and modified by various researchers. ${ }^{1,4-6}$ Each of these techniques has a different entry point and trajectory in the sagittal and axial planes. In 2008, Ching ${ }^{7}$ used a modified Magerl's technique and reported good results and low complication rate. With the different available techniques for LMS insertion, the malposition of these screws can lead to complications. LMS complications can be divided into intraoperative complications (vertebral artery injury [VAI], nerve root injury [NRI], spinal cord injury [SCI], lateral mass fracture [LMF]) and postoperative complications (screw malposition, screw complications like pullout, breakage, or loosening). ${ }^{1}$

The use of three-dimensional (3D) navigation in spine surgery allows the surgeon to navigate the patient's spine by loading a computed tomography (CT) scan to the system preoperatively. ${ }^{8}$ The navigation technology has advanced greatly due to the high speed computers that integrate the navigation data. ${ }^{9}$ The navigation systems can be based on intraoperative two-dimensional (2D)/3D fluoroscopy, CT scan, or magnetic resonance imaging (MRI). The CT-based navigation systems help the spine surgeons to accurately place spinal instrumentation (pedicle screws, LMS, and interbody fusions). The use of either a preoperative CT scan or an intraoperative 3D fluoroscopy-based navigation has the advantage of outlining the bony landmarks compared with the MRI. Registration in the navigation system can be either single-time multilevel registration or the level-by-level registration method. ${ }^{10}$ Registration can be by paired points (3-4 points), surface matching technique, or combined combination of techniques. Checking the accuracy of the navigation at each level before instrumentation is an important indicator for possible reregistration.

The aim of this study is to evaluate the different complications associated with the LMS for the cervical spine fixation screw malposition and compare the $3 \mathrm{D}$ navigation group with the freehand group.

\section{Methods}

\section{Study Population}

We retrospectively studied 40 patients with LMS instrumentation from January 2014 to April 2015 at the Ottawa Hospital. All the included patients had cervical instrumentation with LMS; the 3D navigation technique was used in 20 patients, and the freehand technique was used for the other 20 patients. We studied the LMS in the subaxial spine from C3 to C7.

The inclusion criteria were age 18 years and above, fracture of the subaxial cervical spine or cervical degenerative disc disease associated with myelopathy as an indication, at least 1 level of LMS fixation (2 vertebrae) from C3 to C7, and patients with extension of instrumentation to occiput or the thoracic spine. The exclusion criteria were patients who had previous cervical instrumentation or patients who had $4 \mathrm{~mm}$ diameter LMS.

\section{Surgical Technique for 3D Navigation Group}

In this group, all surgeries were done under general anesthesia. We used CT scan-based navigation, and the images were uploaded to the Stryker navigation system preoperatively. Both the Stryker navigation probe and the array used in the procedures have three spheres. The patients were operated on the prone position, and their heads were fixed to the Mayfield frame. Preoperative antibiotic was also administered. Our approach was midline posterior with subperiosteal paraspinal muscle dissection to the lateral edge of the lateral masses. We identified the levels using a cross-table 10-ray and hooked the navigation array to either the distal or proximal exposed spinous processes. Then, we started the registration using the combined technique, which included paired points (4-5 points) with an acceptable accuracy of $<2 \mathrm{~mm}$, followed by surface match technique- 30 points-to increase the accuracy. ${ }^{11}$ We accepted an error of up to $2 \mathrm{~mm}$ in accuracy; in the case of a larger error, reregistration was considered. The pair point and the surface match techniques were performed on two consecutive vertebrae. The posterior elements of each. We used a single-time multilevel registration and checked our accuracy at each level using the spinous process and the facet joint as a mark to decrease the operative time (-Fig. $\mathbf{1}$ ).

We started our fixation using a matchstick drill to create the pilot holes. Then, we used either the power drill or the manual drill to create the lateral mass holes, aiming our LMS trajectory to be in the superior lateral quadrant. We used either the Oasys system from Stryker or the Synapse system from DePuy Synthes. The sizes of the used LMS were $3.5 \mathrm{~mm}$ $\times 8$ to $16 \mathrm{~mm}$.

\section{Surgical Technique for the Freehand Group}

The above preparation was also followed in this group. We used the modified Magerl's (Ching) technique for cervical spine LMS insertion, in which the entry point was $1.5 \mathrm{~mm}$ caudal and medial to the center of the lateral mass and had a relatively more oblique $\left(30^{\circ}-40^{\circ}\right)$ and steeper $\left(35^{\circ}-45^{\circ}\right)$ trajectory, aiming our LMS trajectory to be in the superior lateral quadrant (Zone 1) (-Fig. 2). 

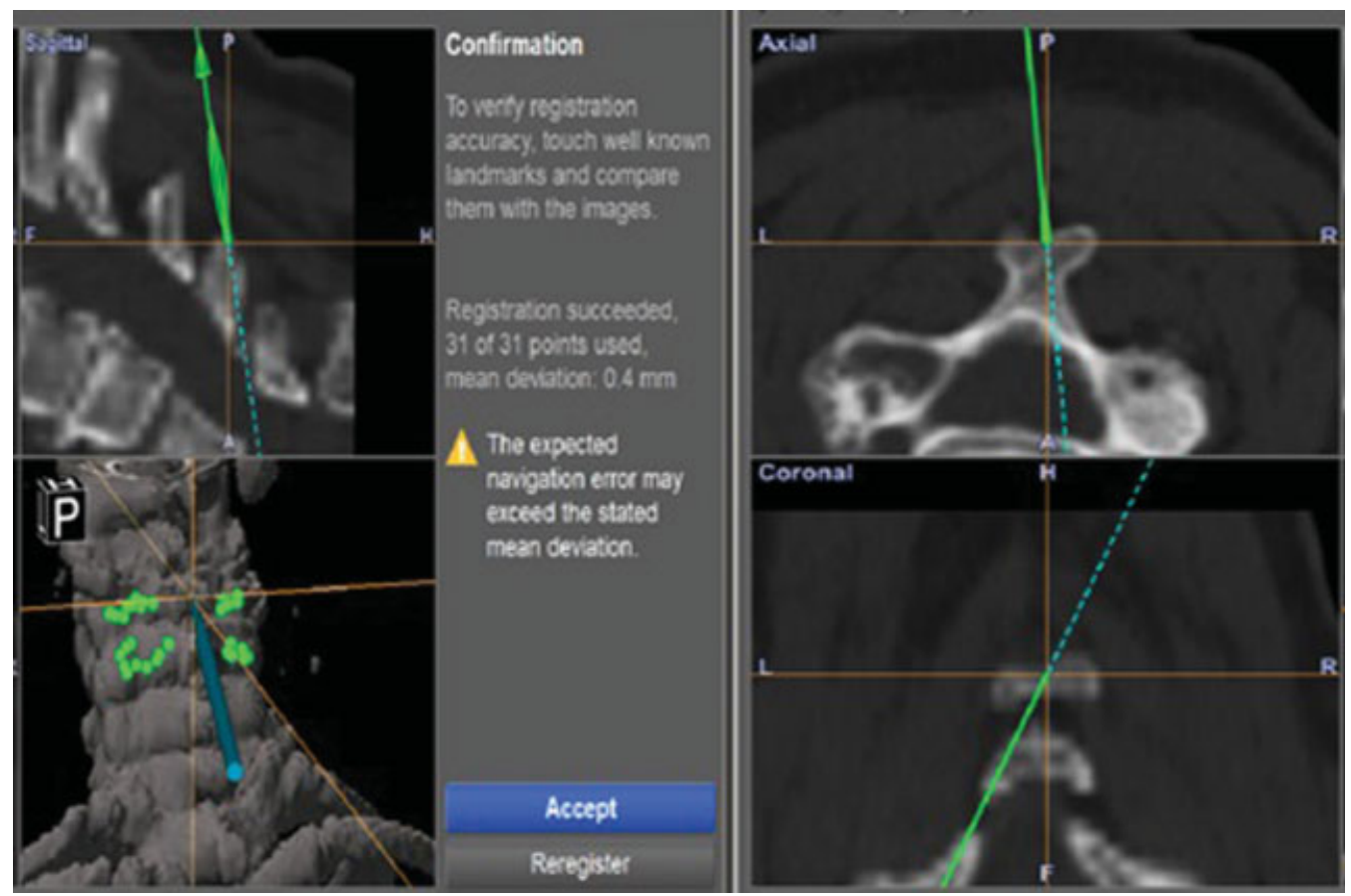

Fig. 1 (A) The surface match registration and (B) confirming registration.

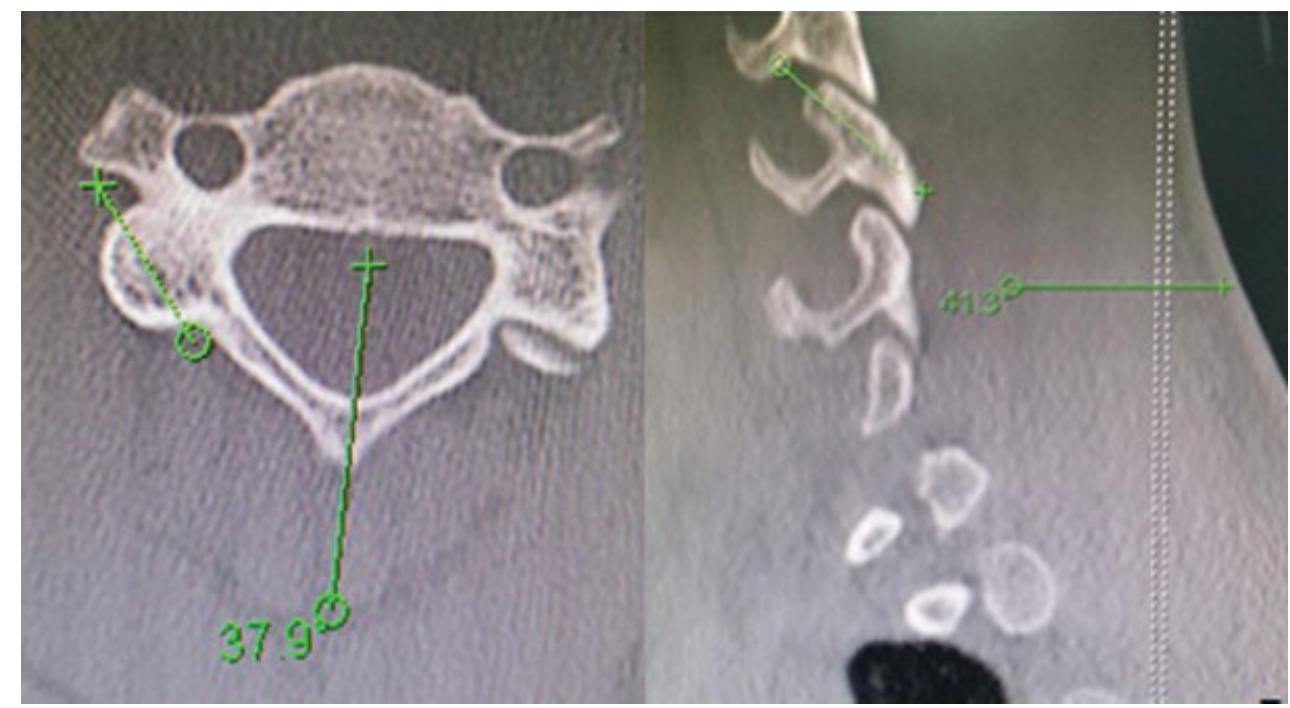

Fig. 2 (A) Axial trajectory. (B) Vertical trajectory.

\section{Follow-Up Assessment}

The patients in both the groups wore a Philadelphia collar for 3 months. All the patients had postoperative serial X-rays and clinical assessment immediately after surgery, and at 3 , 6 , and 12 months' follow-up. All the patients also had cervical spine CT scans 6 weeks after the surgery. The mean follow-up duration was 13 months.

\section{Clinical Assessment}

For clinical assessment, we addressed intraoperative VAI by heavy bleeding ${ }^{12}$ and SCI and NRI by the cerebrospinal fluid leak associated with postoperative neurological deficit. LMF was assessed intraoperatively by any crack induced in the lateral mass while performing the fixation. ${ }^{1}$ The development of any symptoms or signs indicating neurovascular injuries (VIA, SCI, NRI) such as sensory or motor deficits and visual impairment were reviewed from the patient's chart. ${ }^{1}$

\section{CT Scan Assessment}

CT scans were done using $2.5 \mathrm{~mm}$ thickness cuts. The sagittal and axial cuts were assessed by the independent interobserver, who did not contribute to any of the surgeries. The spatial relationship between the screw and the foramen transversarium (FT) was evaluated on axial plane CT images based on the location of the screw tip in relation to the edge of the vertebral artery (VA) foramen. ${ }^{1}$ 


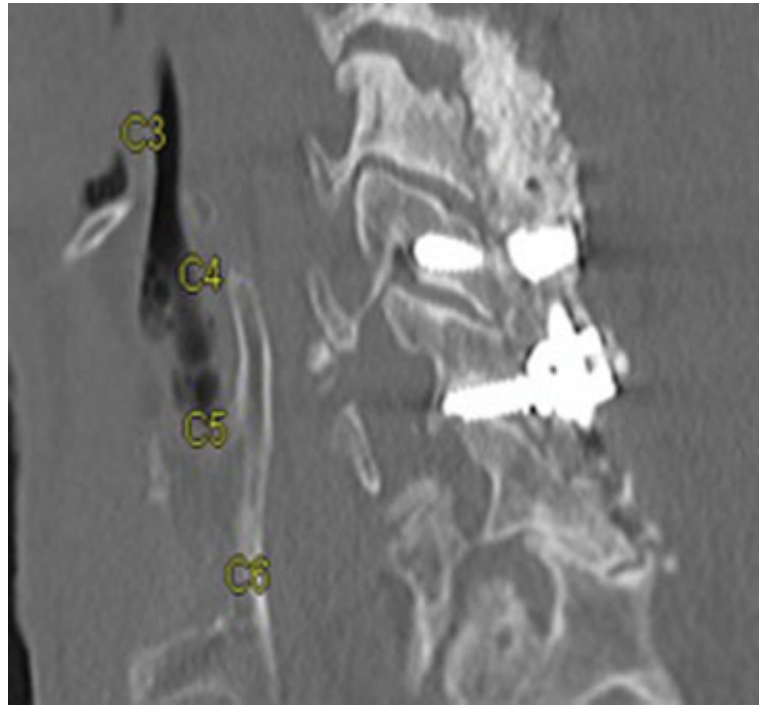

Fig. 3 Screws at Zones 2 and 3 according to Heller's classification in C4 and $C 5$.

"The zones for the tip of the screw are defined by Heller et al as follows: Zone 1 is the superior margin of the superior articular process, Zone 2 includes the ventral portion of the lateral mass that forms the roof of the neuroforamen and the transverse process that protects the nerve root as it exits the neuroforamen, and Zone 3 extends from the inferior origin of the transverse process to the tip of the inferior articular process." 13,14 We defined the screws with breaching tips at Zones 2 and 3 as malpositioned, see - Fig. 3.

\section{Statistical Analysis}

The following data were collected: demographic data (age, sex, etc.), indication for surgical intervention, date of surgery, number of cervical spine levels that were instrumented, number of LMSs at each level, intraoperative events (VAI, LMF, and neurologic injury), use of intraoperative 3D neuronavigation, and cervical spine alignment (postop day 1,3,6, and 12 months' follow-up). The data were stratified into two groups: group 1 patients had their surgery using the freehand technique, and group 2 patients had their surgery using 3D navigation. The analysis was done by comparing the primary outcome, which is screw malposition, and secondary outcome that includes the number of LMS, hospital stay, cervicothoracic/occipitocervical extension, and blood loss between the two groups.

For each subject, the malpositioned screws were collected for each patient (e.g., $0,1,2 \ldots)$. We calculated the percentage of screw malposition among the total number of LMS for each patient. The total number of LMS for each patient was considered as a weighted variable. The weighted arithmetic means and the weighted standard deviation (SD) of the percentage of malpositioned screws were also calculated.

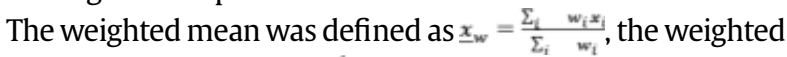
variance was defined $\mathrm{as}_{w}^{2}=\frac{1}{4} \sum_{i} \quad w_{i}\left(x_{i}-\underline{x}_{w}\right)^{2}$, where $w_{\mathrm{i}}$ is the weight for the $i$ th subject, $x_{i}$ is the $i$ th variable value, and the divisor $d$ is $n-1$. The weighted variance is a measure of variability, and it is the sum of the weighted squared distance of data value from the mean divided by the variance divisor, which is defined to be $n-1$.

We calculated the mean, range, and median (95\% confidence interval $[\mathrm{CI}]$ ) for each group demographic data, ratio of intraoperative events for each group, the ratio of misalignment within each group, and ratio of implant failure within each group. The two groups were compared using $t$-test (for continuous variables) and chi-square test (for binomial variables and ratios). We also conducted multivariable analysis for the primary outcome within each group and compared the ratio of the primary outcome between the two groups. We conducted the statistical analysis using the $\alpha$ of 0.05 using Excel and Statistical Analysis Software (SAS).

To compare the difference between these two treatment groups, we applied Wilcoxon rank-sum nonparametric test or Fisher exact test for continuous variables or categorical variables. Two-sided $p$-value of $<0.05$ was considered statistically significant. To compare the percentage of screw malposition between the two treatment groups, the univariate weighted generalized linear model was conducted assuming the percentage and number of malpositions to be gamma distributed. The total number of LMS was used as weighted values, and the GENMOD procedure was applied for this analysis in the SAS (SAS version 9.4 for Windows). The outcome of the model was the percentage of screw malposition.

\section{Results}

The median age of the patients was 64 years, and $60 \%$ of the total patients were males. The median hospital stay was found to be 5 days, and nobody had SCI, VAI, or NRI. The median number of LMS was 8 , and none of the patients had any screw breakage, pull out, or loosening (-Table $\mathbf{1}$ ).

The two groups of patients have been compared in - Table 2 for better evaluation of the patients' demographics and clinical outcomes.

As shown in - Table 2, there is no statistically significant difference between the two groups in terms of demographic data (age, gender), number of LMS per patient, number of trauma patients, and extension of instrumentation. There was also no significant difference between the two groups in terms of LMF, blood loss, and hospital stay, but the two groups showed a significant difference in the operation time $(p=0.045)$. That is because the time required for the application and registration of the $3 \mathrm{D}$ navigation. Also, we compared each level of instrumentation and showed no significant difference between the two groups ( - Table 3 ).

In the 3D navigation system group, 144 screws were used in total, and 16 screws were malpositioned. On the other hand, in the freehand technique group, the total number of screws was 140 , and the number of malpositioned screws was 27 .

Among 284 total number of LMS, there were $19.3 \%$ screw malpositions in the freehand technique (140 LMS), and $11.1 \%$ malpositions in the 3D neuronavigation technique (144 LMS). To compare percentage of malpositions between two treatment groups, weighted generalized linear model was conducted ( - Table 4 ). There was a significant difference between the percentage of screw malposition between the 
Use of 3D Navigation in Subaxial Cervical Spine Arab et al. e5

Table 1 Shows the basic information of all the 40 patients

\begin{tabular}{|c|c|c|}
\hline Demographics & & \\
\hline Age $(y)$ & & \\
\hline N & 40 & \\
\hline Mean \pm SD & 63. & \\
\hline Median (interquartiles) & 64 & \\
\hline Range & 44 , & \\
\hline Gender & & \\
\hline Female & 16 & $(40.00 \%)$ \\
\hline Male & 24 & $(60.00 \%)$ \\
\hline Clinical outcomes & & \\
\hline Treatment group & & \\
\hline Freehand technique & 20 & (50.00\%) \\
\hline 3D navigation system & 20 & $(50.00 \%)$ \\
\hline Screw/Rod breakage & & \\
\hline No & 40 & $(100.00 \%)$ \\
\hline Yes & 0 & $(0.00 \%)$ \\
\hline Screw pullout & & \\
\hline No & 40 & $(100.00 \%)$ \\
\hline Yes & 0 & $(0.00 \%)$ \\
\hline Screw loosening & & \\
\hline No & 40 & $(100.00 \%)$ \\
\hline Yes & 0 & $(0.00 \%)$ \\
\hline Hospital stays (d) & & \\
\hline N & 40 & \\
\hline Mean \pm SD & 7.3 & \\
\hline Median (interquartiles) & $5(3$ & \\
\hline Range & 2,2 & \\
\hline Vertebral artery injury & & \\
\hline No & 40 & $(100.00 \%)$ \\
\hline Yes & 0 & $(0.00 \%)$ \\
\hline Spinal cord injury & & \\
\hline No & 40 & $(100.00 \%)$ \\
\hline Yes & 0 & $(0.00 \%)$ \\
\hline Nerve root injury & & \\
\hline No & 40 & $(100.00 \%)$ \\
\hline Yes & 0 & $(0.00 \%)$ \\
\hline Instrumentation & & \\
\hline Thoracic & & \\
\hline No & 30 & $(75.00 \%)$ \\
\hline Yes & 10 & $(25.00 \%)$ \\
\hline Occipitocervical & & \\
\hline No & 36 & $(90.00 \%)$ \\
\hline Yes & 4 & (10.00\%) \\
\hline
\end{tabular}

Abbreviation: SD, standard deviation.

3D navigation and freehand technique $(p=0.0103)$ (-Table 5). Patients using the freehand technique are more likely to have higher percentage of screw malpositions compared with those using the 3D navigation system (due
Table 2 Demographics and clinical outcomes

\begin{tabular}{|c|c|c|c|}
\hline & $\begin{array}{l}\text { 3D navigation } \\
\text { group } \\
(n=20)\end{array}$ & $\begin{array}{l}\text { Freehand } \\
\text { group } \\
(n=20)\end{array}$ & $p$-Value ${ }^{a}$ \\
\hline \multicolumn{4}{|l|}{ Age $(y)$} \\
\hline Mean \pm SD & $62.0 \pm 13.1$ & $64.6 \pm 8.4$ & \multirow[t]{2}{*}{0.2847} \\
\hline Range & $44-93$ & $44-81$ & \\
\hline \multicolumn{4}{|l|}{ Gender } \\
\hline Female & 9 (45\%) & 7 (35\%) & \multirow[t]{2}{*}{0.7475} \\
\hline Male & 11 (55\%) & 13 (65\%) & \\
\hline $\begin{array}{l}\text { No. of } \\
\text { LMS/patient } \\
\text { median }\end{array}$ & 8 & 8 & 0.9772 \\
\hline $\begin{array}{l}\text { Pathology of } \\
\text { trauma }\end{array}$ & $8(40 \%)$ & $6(30 \%)$ & 0.7411 \\
\hline $\begin{array}{l}\text { Cervicothoracic } \\
\text { extension }\end{array}$ & $6(30 \%)$ & $4(20 \%)$ & 0.716 \\
\hline $\begin{array}{l}\text { Occipitocervical } \\
\text { extension }\end{array}$ & $1(5 \%)$ & $3(15 \%)$ & 0.605 \\
\hline $\begin{array}{l}\text { Operative } \\
\text { time }(\mathrm{h}) \\
(\text { mean } \pm \mathrm{SD})\end{array}$ & $5.1 \pm 1.32$ & $4.35 \pm 1.67$ & 0.0453 \\
\hline $\begin{array}{l}\text { Blood loss } \\
(\text { mean } \pm \text { SD) }\end{array}$ & $615 \pm 629.8$ & $574.7 \pm 350.9$ & 0.3766 \\
\hline IOM & 7 (35\%) & $6(30 \%)$ & 0.7357 \\
\hline LMF & $1(5 \%)$ & $4(20 \%)$ & 0.3416 \\
\hline $\begin{array}{l}\text { Neurological } \\
\text { deficit }\end{array}$ & $3(15 \%)$ & $1(5 \%)$ & 0.6050 \\
\hline Reoperation & $0(0 \%)$ & $2(10 \%)$ & 0.4872 \\
\hline $\begin{array}{l}\text { Hospital stay }(\mathrm{d}) \\
(\text { mean } \pm \text { SD) }\end{array}$ & $8.1 \pm 5.9$ & $6.5 \pm 5.0$ & 0.4536 \\
\hline
\end{tabular}

Abbreviations: IOM, intraoperative monitoring; LMF, lateral mass fracture; LMS, lateral mass screw; SD, standard deviation.

${ }^{a} p$-Value of $<0.05$ was considered statistically significant.

Table 3 Each level instrumentation

\begin{tabular}{|l|l|l|}
\hline Level & Freehand group & 3D navigation group \\
\hline C3 & 30 & 30 \\
\hline C4 & 33 & 39 \\
\hline C5 & 34 & 39 \\
\hline C6 & 31 & 32 \\
\hline C7 & 12 & 4 \\
\hline Total & 140 & 144 \\
\hline
\end{tabular}

to negative coefficient). The goodness-of-fit shows how well our assumption of gamma distribution fits the real data. The scaled deviation and scaled Pearson's chi-squared test were both close to one, indicating that the underlying distribution was indeed close to the gamma distribution.

There was also a significant difference in the number of screw malpositions between both the techniques ( $p=0.0323$ ). The patients using the freehand technique are more likely to have a higher number of screw malpositions compared with 
Table 4 Shows the weighted mean percentage of screw malpositions

\begin{tabular}{|l|l|l|l|}
\hline & $\begin{array}{l}\text { Total } \\
\text { (no. of screws = 284) }\end{array}$ & $\begin{array}{l}\text { Freehand technique } \\
\text { (no. of screws = 140) }\end{array}$ & $\begin{array}{l}\text { 3D navigation system } \\
\text { (no. of screws = 144) }\end{array}$ \\
\hline No. of subjects & 40 & 20 & 20 \\
\hline No. of screws & 284 & 140 & 144 \\
\hline \% of screw malpositions & \multicolumn{1}{l}{} \\
\hline Weighted mean \pm SD & $15.14 \pm 41.00$ & $19.29 \pm 49.59$ & $11.11 \pm 27.22$ \\
\hline Median (interquartiles) & $12.5(0,25)$ & $14.6(0,25)$ & $12.5(0,17)$ \\
\hline Range & 0,57 & 0,57 & 0,33 \\
\hline Screw malpositions & \multicolumn{1}{l}{} \\
\hline Weighted mean \pm SD & $1.10 \pm 2.96$ & $1.36 \pm 3.56$ & $0.85 \pm 2.09$ \\
\hline Median (interquartiles) & $1.0(0,2)$ & $1.0(0,2)$ & $1.0(0,1)$ \\
\hline Range & 0,4 & 0,4 & 0,2 \\
\hline
\end{tabular}

Abbreviation: SD, standard deviation.

Table 5 Comparing the percentage of screw malpositions

\begin{tabular}{|l|l|l|l|}
\hline $\begin{array}{l}\text { Comparing the } \\
\text { percentage of } \\
\text { screw malpositions }\end{array}$ & Coefficient & SE & $p$-Value \\
\hline Intercept & 3.3367 & 0.1244 & $<0.0001$ \\
\hline $\begin{array}{l}\text { Group (3D navigation } \\
\text { versus freehand) }\end{array}$ & -0.4587 & 0.1788 & 0.0103 \\
\hline
\end{tabular}

Abbreviation: SE, standard error.

Note: Goodness of fit: Scaled deviance $=1.1228$; Scaled Pearson $x^{2}=1.1139$.

Table 6 Comparing no. of screw malposition

\begin{tabular}{|l|l|l|l|}
\hline $\begin{array}{l}\text { Comparing no. of } \\
\text { screw malposition }\end{array}$ & Coefficient & SE & $p$-Value \\
\hline Intercept & 0.6879 & 0.1247 & $<0.0001$ \\
\hline $\begin{array}{l}\text { Group (3D navigation } \\
\text { versus freehand) }\end{array}$ & -0.3837 & 0.1791 & $\mathbf{0 . 0 3 2 3}$ \\
\hline
\end{tabular}

Abbreviation: SE, standard error.

Note: Goodness of fit: Scaled deviance $=1.1230$; Scaled Pearson $x^{2}=1.1672$.

those using the 3D navigation system (due to negative coefficient) ( - Table 6 ).

- Table 7 shows coefficient, standard error (SE) of coefficient, and $p$-value of each clinical predictive factor; the goodness-of-fit shows how well our assumption of gamma distribution fits the real data. If the scaled deviation and scaled Pearson's chi-square are both closer to one, it indicates that the underlying distribution is indeed close to a gamma distribution. In the univariate weighted generalized linear regression analysis, gender has a borderline $p$-value of 0.0593 .

In the multivariate analysis, all significant variables obtained from the univariate generalized linear model were put into one big model. We also put gender into the multiple regression model due to its borderline $p$-value. In the below model ( - Table 8), only LMF remained significant $(p=0.0294)$ after adjusting for other factors. The patients with LMF have a significantly higher percentage of screw malpositions compared with others. The weighted mean of screw malposition percentage was $39.4 \%$ in patients with LMF and $12.0 \%$ in patients without LMF.

\section{Discussion}

The use of LMS in cervical spine instrumentation has been proven to be effective in stabilizing the cervical spine with various kinds of pathology. ${ }^{7,12,15-18}$ The usage of the polyaxial screw with rods is the principal device of choice for posterior stabilization of the cervical spine, especially when the upward or downward extension is required., ${ }^{7,19}$

Both cervical pedicle screws and LMS have their advantages and disadvantages. Cervical pedicle screw instrumentation offers rigid fixation but with risk to VAI. ${ }^{7,20,21}$ Unlike cervical pedicle screws, LMS placement requires a shorter learning period and is a more straightforward surgical procedure. ${ }^{7}$ The principal complications caused by LMS malposition are a violation of vertebral arteries and cervical NRI. ${ }^{22}$

We used the Ching technique, a simple and uniform method for placing LMS from C3 to C7, by proposing a modification technique that shifted the screw entry point to $1.5 \mathrm{~mm}$ medial and inferior to the geometrical center of the LMS. ${ }^{7}$ In 1995, Pait et $\mathrm{al}^{23}$ divided the lateral cervical mass (articular pillars of the cervical spine) into quadrants and concluded that the superior lateral quadrant was the "safe quadrant" for placing LMS. The Ching technique entry point combined with the trajectory allows also to aim at the "safe quadrant." 24,25 One of the main reasons we can follow such a greatly angulated trajectory is the development of polyaxial screws. ${ }^{7}$ We used the modified Magerl technique (Ching) because it is safe for the VA and the spinal nerve. Overall, the nerve and artery were safe from compromise at levels $\mathrm{C} 3$ to $\mathrm{C} 6$ with lateral angulation of $20^{\circ}$, $25^{\circ}$ (standard), and $30^{\circ} .26$

Generally, the application of 3D neuronavigation techniques in the cervical spine appears to increase the accuracy, with the misplacement rates ranging from 2 to $40 \%$. $^{9,27,28}$ Holly et al reported that the paired point matching 
Table 7 The coefficient, SE of coefficient, and p-value of each clinical predictive factor

\begin{tabular}{|c|c|c|c|c|c|}
\hline Predictive factor & Coefficient & SE & $p$-Value ${ }^{a}$ & Scaled deviance & Scaled Pearson $\mathrm{x}^{2}$ \\
\hline IOM (Yes versus No) & 0.3418 & 0.2027 & 0.0917 & 1.127 & 1.313 \\
\hline Operation time (continuous) & 0.1091 & 0.1226 & 0.3736 & 1.131 & 1.304 \\
\hline Operation time $\geq 4.3$ versus $<4.3$ & 0.2789 & 0.1938 & 0.1502 & 1.129 & 1.338 \\
\hline Blood loss (continuous) & 0.1384 & 0.1278 & 0.2790 & 1.130 & 1.381 \\
\hline Blood loss $\geq 450$ versus $<450$ & 0.1646 & 0.2012 & 0.4132 & 1.131 & 1.325 \\
\hline Neurological status (deficit versus Intact) & 0.2271 & 0.3511 & 0.5179 & 1.131 & 1.295 \\
\hline Age $(y)$ & 0.0047 & 0.0106 & 0.6596 & 1.132 & 1.353 \\
\hline Age $(\geq 65$ y versus $<65$ y) & 0.0690 & 0.1995 & 0.7295 & 1.132 & 1.349 \\
\hline Gender (Male versus Female) & 0.3747 & 0.1987 & 0.0593 & 1.127 & 1.160 \\
\hline Hospital stay $(\geq 5 \mathrm{~d}$ versus $<5 \mathrm{~d}$ ) & -0.1777 & 0.1960 & 0.3647 & 1.130 & 1.316 \\
\hline
\end{tabular}

Abbreviation: IOM, intraoperative monitoring; SE, standard error.

${ }^{a} p$-Value $<0.05$ was considered statistically significant.

Table 8 After adjusting of other factors

\begin{tabular}{|l|l|l|l|l|l|}
\hline Predictive factor & Coefficient & SE & $p_{\text {-Value }}{ }^{a}$ & Scaled deviance & ${\text { Scaled Pearson } \mathbf{X}^{2}}$ \\
\hline Intercept & 2.8615 & 0.1425 & $<0.0001$ & 1.270 & 1.266 \\
\hline Lateral mass fracture (Yes versus No) & $\mathbf{0 . 4 8 6 9}$ & $\mathbf{0 . 2 2 3 5}$ & $\mathbf{0 . 0 2 9 4}$ & & \\
\hline Gender (Male versus Female) & 0.2597 & 0.1619 & 0.1086 & & \\
\hline Reoperation (Yes versus No) & 0.4374 & 0.4397 & 0.3198 & & \\
\hline Thoracic (Yes versus No) & -0.2676 & 0.1924 & 0.1642 & & \\
\hline
\end{tabular}

Abbreviation: SE, standard error.

${ }^{a} p$-Value $<0.05$ was considered statistically significant.

supplemented with surface matching resulted in a lower mean registration error than the paired point matching alone. ${ }^{19}$ The intertechnique difference in navigational error was nearly equivalent ( $1.3 \mathrm{~mm}$ compared with $1.4 \mathrm{~mm}$ ) and statistically insignificant. $^{19}$

LMS fixation is a relatively safe procedure; however, there are several complications that may be encountered during LMS insertion, such as VAI, NRIs, facet violation, and LMF, 1,16 due to LMS malposition. In the analysis of clinical results, Graham et al and Roche et al claimed that the screw positioning is the main factor leading to the complications related to LMS. 1,29,30 "In cadaveric experiments simulating the surgical procedure, Heller et al, ${ }^{14}$ Seybold et al, ${ }^{13}$ and Barrey et $\mathrm{al}^{31}$ showed a correlation between the risk of these complications and an inappropriate screw trajectory angle."1 In our study, there were $19.3 \%$ of screw malpositions in the freehand technique (140 LMS) and 11.1\% of malpositions in the 3D navigation system (144 LMS). There was a significant difference in the percentage of screw malpositions between the $3 \mathrm{D}$ navigation and freehand techniques $(p=0.0103)$. In our study, there were no VAIs, SCI, or NRI.

Several reports have demonstrated the malposition of LMS to be a potential risk factor for facet violation (FV) and FT that may lead to complications. Ebraheim et $\mathrm{a}^{32}$ reported that the violation of the inferior facet of the most caudal facet joint may lead to revision surgery to extend the fixation. ${ }^{1}$ Moreover, Shinichi stated that the violation of FT or FV is related to the malposition of LMS trajectory in the axial or sagittal planes, respectively. ${ }^{1}$ The anatomic study of An et al $^{4}$ observed that the nerve roots' exit point was at the anterolateral portion of the superior facet and that the malposition of LMS with the violation of the superior facet may lead to NRI.

A few clinical papers referred to the LMF with an incidence of 1.6 to $4 \%{ }^{1,18,33-35}$ Our study showed $15 \%$ LMF in the freehand technique compared with $5 \%$ in the 3D neuronavigation technique with an insignificant $p$-value (0.3416). From the statistical analysis, the patients with LMF have a significantly higher percentage of screw malpositions compared with others. We followed the same management of Inoue et al to deal with intraoperative LMF by abandoning screw insertion at the corresponding level of all lateral masses with fractures. ${ }^{33}$ Katonis et al reported that the lateral screw trajectory (malposition) increased the incidence of $\mathrm{LMF}^{33,34}$

The limitation of this study is that the surgeries were performed by multiple surgeons, and this could affect the accuracy of the entry point and screw trajectories. However, the strength factor of our study is that we had a postoperative CT scan for each patient. We also involved an independent interobserver to analyze the screws. In addition to the LMS fixation, we used the modified Magerl technique, which reduced the complication rate for the freehand group because of its safe trajectories. The use of the 3D navigation for the second group with preop loading of CT scans also gave us better trajectories and starting points. 


\section{Conclusion}

The use of 3D navigation decreased the malpositions in LMS instrumentation compared with the freehand technique (modified Magerl). Also, the patients with LMF have a significantly higher percentage of screw malpositions compared with others. The study did not show any significant difference in VAI, NRI, SCI, screws complications, or blood loss between the two groups. We recommend that future studies should further investigate the effect of malpositions on the biomechanics of the cervical spine and its clinical application.

\section{Conflict of Interest}

None.

\section{References}

1 Inoue S, Moriyama T, Tachibana T, et al. Cervical lateral mass screw fixation without fluoroscopic control: analysis of risk factors for complications associated with screw insertion. Arch Orthop Trauma Surg 2012;132(07):947-953

2 Yoshihara H, Passias PG, Errico TJ. Screw-related complications in the subaxial cervical spine with the use of lateral mass versus cervical pedicle screws: a systematic review. J Neurosurg Spine 2013;19(05):614-623

3 Roy-Camille R, Gaillant G, Bertreaux D. Early management of spinal injuries. In: McKibben B, ed. Recent Advances in Orthopedics. Edinburgh: Churchill-Livingstone; 1979:57-87

4 An HS, Gordin R, Renner K. Anatomic considerations for platescrew fixation of the cervical spine. Spine 1991;16(10, Suppl): S548-S551

5 Anderson PA, Henley MB, Grady MS, Montesano PX, Winn HR. Posterior cervical arthrodesis with $\mathrm{AO}$ reconstruction plates and bone graft. Spine 1991;16(3, Suppl)S72-S79

6 Jeanneret B, Magerl F, Ward EH, Ward JC. Posterior stabilization of the cervical spine with hook plates. Spine 1991;16(3, Suppl): S56-S63

7 Wu JC, Huang WC, Chen YC, Shih YH, Cheng H. Stabilization of subaxial cervical spines by lateral mass screw fixation with modified Magerl's technique. Surg Neurol 2008;70(01, Suppl 1): S1, 25-33, discussion S1, 33

8 Nottmeier E. Computer-assisted navigation for minimally invasive spine surgery. In: Minimally Invasive Spine Surgery Techniques, Evidence, and Controversies. Davos: AOSPINE; 2012:67-68

9 Tjardes T, Shafizadeh S, Rixen D, et al. Image-guided spine surgery: state of the art and future directions. Eur Spine J 2010;19(01):25-45

10 Tauchi R, Imagama S, Sakai Y, et al. The correlation between cervical range of motion and misplacement of cervical pedicle screws during cervical posterior spinal fixation surgery using a CT-based navigation system. Eur Spine J 2013;22(07):1504-1508

11 Ra IH, Min WK. Radiographic and clinical assessment of a freehand lateral mass screw fixation technique: is it always safe in subaxial cervical spine? Spine J 2014;14(09):2224-2230

12 Pateder DB, Carbone JJ. Lateral mass screw fixation for cervical spine trauma: associated complications and efficacy in maintaining alignment. Spine J 2006;6(01):40-43

13 Seybold EA, Baker JA, Criscitiello AA, Ordway NR, Park CK, Connolly PJ. Characteristics of unicortical and bicortical lateral mass screws in the cervical spine. Spine 1999;24(22):2397-2403

14 Heller JG, Carlson GD, Abitbol JJ, Garfin SR. Anatomic comparison of the Roy-Camille and Magerl techniques for screw placement in the lower cervical spine. Spine 1991;16(10, Suppl)S552-S557
15 Deen HG, Birch BD, Wharen RE, Reimer R. Lateral mass screw-rod fixation of the cervical spine: a prospective clinical series with 1-year follow-up. Spine J 2003;3(06):489-495

16 Heller JG, Silcox DH III, Sutterlin CE III. Complications of posterior cervical plating. Spine 1995;20(22):2442-2448

17 Roy-Camille R, Saillant G, Laville C, Benazet JP. Treatment of lower cervical spinal injuries-C3 to C7. Spine 1992;17(10, Suppl) S442-S446

18 Sekhon LH. Posterior cervical lateral mass screw fixation: analysis of 1026 consecutive screws in 143 patients. J Spinal Disord Tech 2005;18(04):297-303

19 Holly LT, Bloch O, Johnson JP. Evaluation of registration techniques for spinal image guidance. J Neurosurg Spine 2006;4(04):323-328

20 Horn EM, Hott JS, Porter RW, Theodore N, Papadopoulos SM, Sonntag VK. Atlantoaxial stabilization with the use of C1-3 lateral mass screw fixation. Technical note. J Neurosurg Spine 2006;5 (02):172-177

21 Abumi K, Shono Y, Ito M, Taneichi H, Kotani Y, Kaneda K. Complications of pedicle screw fixation in reconstructive surgery of the cervical spine. Spine 2000;25(08):962-969

22 Xu R, Haman SP, Ebraheim NA, Yeasting RA. The anatomic relation of lateral mass screws to the spinal nerves. A comparison of the Magerl, Anderson, and An techniques. Spine 1999;24(19): 2057-2061

23 Pait TG, McAllister PV, Kaufman HH. Quadrant anatomy of the articular pillars (lateral cervical mass) of the cervical spine. J Neurosurg 1995;82(06):1011-1014

24 Xu R, Ebraheim NA, Klausner T, Yeasting RA. Modified Magerl technique of lateral mass screw placement in the lower cervical spine: an anatomic study. J Spinal Disord 1998;11(03):237-240

25 Ebraheim N. Posterior lateral mass screw fixation: anatomic and radiographic considerations. Univ Pennsylvania Orthopaed J 1999; 12:66-72

26 Merola AA, Castro BA, Alongi PR, et al. Anatomic consideration for standard and modified techniques of cervical lateral mass screw placement. Spine J 2002;2(06):430-435

27 Hott JS, Deshmukh VR, Klopfenstein JD, et al. Intraoperative Iso-C C-arm navigation in craniospinal surgery: the first 60 cases. Neurosurgery 2004;54(05):1131-1136, discussion 1136-1137

28 Hott JS, Papadopoulos SM, Theodore N, Dickman CA, Sonntag VK. Intraoperative Iso-C C-arm navigation in cervical spinal surgery: review of the first 52 cases. Spine 2004;29(24):2856-2860

29 Graham AW, Swank ML, Kinard RE, Lowery GL, Dials BE. Posterior cervical arthrodesis and stabilization with a lateral mass plate. Clinical and computed tomographic evaluation of lateral mass screw placement and associated complications. Spine 1996;21 (03):323-328, discussion 329

30 Roche S, de Freitas DJ, Lenehan B, Street JT, McCabe JP. Posterior cervical screw placement without image guidance: a safe and reliable practice. J Spinal Disord Tech 2006;19(06):383-388

31 Barrey C, Mertens P, Jund J, Cotton F, Perrin G. Quantitative anatomic evaluation of cervical lateral mass fixation with a comparison of the Roy-Camille and the Magerl screw techniques. Spine 2005;30(06):E140-E147

32 Ebraheim NA, Xu R, Challgren E, Yeasting RA. Quantitative anatomy of the cervical facet and the posterior projection of its inferior facet. J Spinal Disord 1997;10(04):308-316

33 Inoue S, Moriyama T, Tachibana T, et al. Risk factors for intraoperative lateral mass fracture of lateral mass screw fixation in the subaxial cervical spine. J Neurosurg Spine 2014;20(01):11-17

34 Katonis P, Papadakis SA, Galanakos S, et al. Lateral mass screw complications: analysis of 1662 screws. J Spinal Disord Tech 2011; 24(07):415-420

35 Katonis P, Papadopoulos CA, Muffoletto A, Papagelopoulos PJ, Hadjipavlou AG. Factors associated with good outcome using lateral mass plate fixation. Orthopedics 2004;27(10):1080-1086 